\title{
Mães em contexto de cárcere: ambiente, práticas de cuidado e conhecimentos sobre desenvolvimento
}

\author{
Marilia Zara Gentil de Oliveira* \\ Celina Maria Colino Magalhães**
}

\begin{abstract}
Resumo
O estudo analisou o contexto de cárcere a partir da teoria do Nicho de Desenvolvimento: ambiente físico e social, psicologia dos cuidadores e as práticas de cuidado. Participaram deste estudo 16 mães custodiadas na Unidade Materno Infantil. Utilizou-se para coleta dos dados um roteiro de entrevista semiestruturada e Inventário de conhecimento do Desenvolvimento Infantil (KIDI). Os resultados evidenciaram que 62\% das mães acertaram as questões do inventário,sendo os melhores resultados obtidos em assertivas relacionadas a categoria Saúde e Segurança $(71,87 \%)$ e Princípios do desenvolvimento $(64,34 \%$ ). A estrutura do ambiente físico e social foi uma variávelimportante no conhecimento das mães as questões ligadas as categorias de saúde e segurança e de princípios.

Palavras-chave: mãe; bebê; desenvolvimento infantil;
\end{abstract}

\begin{abstract}
The studyanalyzedtheprisoncontextfromtheNicheDevelopmenttheory: physicaland social environment, caregiverpsychologyandcarepractices. Participated16 mothersguarded in the MaternalandChild Unit. A semi-structured interview script and a ChildDevelopmentKnowledgeInventory (KIDI) wereused for data collection. The resultsshowedthat $62 \%$ ofthemothersansweredrightquestionsabouttheinventory, thebestresultsbeingobtained in assertionsrelatedto Health andSafety (71.87\%) andDevelopmentPrinciples (64.34\%). The structureofthephysicaland social environmentwasanimportantvariable in theknowledgeofmotherstheissuesrelatedtohealthandsafetycategoriesandprinciples.

Keywords:mother; baby; childdevelopment;
\end{abstract}

* Psicóloga pela UNAMA - Pós-Graduação em Terapia e Orientação Familiar Sistêmica (UNAMA). Mestrado em Ecologia do Desenvolvimento Humano pela UFPA.

** Psicóloga pela UfPA, Mestrado em Psicologia - Teoria e Pesquisa do Comportamento UFPA. Doutora em Psicologia Experimental pela USP. 


\section{Introdução}

O número crescente de mulheres nos sistemas prisionais abriu espaço à realização de estudos voltados para essa população, em especial mulheres grávidas e que permanecem com seus filhos após o parto. Diversos autores reconhecem que apesar da preocupação e urgência de mudanças apontadas por relatórios públicos, ainda existe a necessidade de mais pesquisas considerando que na maioria das vezes os estudos realizados são voltados para a criminalidade e violência, deixando ao largo questões referentes a estrutura dos espaços penitenciários, as mulheres custodiadas com seus filhos e as práticas de cuidado dessas mães nas unidades prisionais (Armelin, Mello \&Gauer, 2010; Rita, 2006; Viafore, 2005)

Dados do Ministério da Justiça, referente aos anos de 2007 a 2012 indicaram um crescimento de $42 \%$ da população prisional feminina, que representa mais de 35.000 mulheres encarceradas (Brasil, 2012). Além do crescente aumento de mulheres custodiadas no Brasil, soma-se a visível presença de gestantes nos ambientes prisionais brasileiros. Estes locais possuem diferentes critérios de atendimento as necessidades básicas dessas mulheres, chegando a não conseguir suprir as determinações previstas em lei (Santos, 2011).

Estudos voltados para a compreensão da realidade vivida por mães no cárcere, indicaram a falta de acompanhamento gestacional das grávidas, de orientação nutricional,de realização de exames ginecológicos, preventivos contra o câncer, mamografias e outros exames indispensáveis à boa saúde da mulher-mãe (Souza \& Ferreira, 2012).

O relatório sobre mulheres custodiadas no Brasil enfatiza que as mães grávidas sofrem mais com o descumprimento das normas constitucionais, como não ter garantido o seu direito à assistência médica especializada durante o período gestacional. Devido essa ausência de atendimento, alguns exames laboratoriais ou de imagem não são realizados, pondo em risco a saúde da mulher e do feto, inclusive de contaminação em casos de doenças sexualmente transmissíveis. Além disso os espaços destinados para as díades, nas unidades prisionais e nas cadeias públicas, não são apropriados para os acomodar (CEJIL, 2007).

No que concerne as práticas de cuidado adotadas pelas mães, deve-seconsiderar as limitações impostas pelo próprio ambiente que podem ou não possibilitar práticas adequadas e facilitadoras do desenvolvimento infantil, como por exemplo, a prática do aleitamento materno em contexto de cárcere, visto que é um ato que vislumbra diversos aspectos positivos para a mãe e o bebê, e seu cumprimento deve ser efetivo.

Sobre o direito à amamentação e as estratégias pensadas para a sua efetivação no contexto do cárcere, as mães e gestantes demonstram conhecer pouco sobre seus direitos e a possibilidade de poder amamentar seus filhos no ambiente prisional apesar de reconhecerem a importância e os benefícios que essa prática traz para o desenvolvimento infantil (Dalmácio, Cruz \& Cavalcante, 2014).

O conceito de Nicho de Desenvolvimento proposto porSuper e Harkness (1986), mostra-se sensível, para discutir o desenvolvimento em contexto de cárcere. O Nichodesenvolvimentalé composto por três subsistemas: o primeiro é caracterizado pelo ambiente físico e social da criança; o segundo é caracterizado pelas práticas de cuidado e de criação destinadas a ela e que também são compartilhadas pela comunidade em que estão inseridas e o terceiro se refere à psicologia dos cuidadores, incluindo o conhecimento sobre desenvolvimento infantil, os valores e as crenças voltadas para a criança.

Estudos desenvolvidos com o conceito do Nicho Desenvolvimental mostram como os aspectos do ambiente físico e social estariam relacionados a determinadas questões do desenvolvimento, assim como a relevância das práticas adotadas pelos cuidadores. Com o objetivo de investigar aspectos relacionados a precocidade de crianças africanas em relação ao seu desenvolvimento motor, foi realizada uma pesquisa com 64 bebês e suas famíliasde uma comunidade rural do Quênia. Nos resultados, foi possível verificar que os bebês quenianos adquiriram mais cedo habilidades motoras (como sentar e andar) quando comparados aos bebês americanos. Foi observado que estas habilidades eram ensinadas por suas mães e praticadas no decorrer das suas rotinas diárias. O estudo mostrou que $80 \%$ das mães quenianas ensinavam seus bebês a sentar, levantar e andar, o que pode explicar o fato de que, neles, tais habilidades estão mais avançadas do que nas americanas (Super, 1976).Sintetizando a influência exercida nesse padrão específico de desenvolvimento motor, pode-se dizer que existe a relação com o ambiente físico e social das crianças.

Um diferente estudo desenvolvido em Kokwet, localidade rural do Quênia, identificou que durante o dia, os bebês eram presos junto ao corpo de suas mães, que os levavam aonde forem. À noite, eles dormiam em contato com elas e, quando mais velhos, em contato com outras crianças de suas famílias. Percebeu-se que esta prática de dormir ao lado da mãe nos primeiros meses de vida 
favoreceu a amamentação. Porém, a longo prazo, a prática influencia o padrão de sono noturno dos bebês. Normalmente os bebês ocidentais, por volta de seis semanas de vida, começam a se aproximar de um padrão de sono dia/noite, o que não era comum entre osbebês da zona rural do Quênia (Harkness\&Super, 1992).

Assim os estudos que se propõem a investigar o desenvolvimento infantil, precisam atentar para os contextos físico, social, histórico e cultural do indivíduo.

Levando em consideração todos os aspectos levantados até aqui, o presente estudo objetivou analisar o contexto de cárcere a partir do modelo teórico do Nicho de Desenvolvimento considerando o ambiente físico e social, a psicologia das cuidadoras (crenças, cognições etc) e as suas práticas de cuidado. Ressalta-se queaperspectiva do nicho enfatiza a integração desses fatores fundamentadas em uma compreensão sistêmica e interdependente.

\section{Método}

\section{Participantes}

A pesquisa envolveu 16 mães custodiadas na Unidade Materno Infantil da SUSIPE, no período de 2015 a 2016, queforam selecionadas por conveniência e atenderam os seguintes critérios de inclusão: 1 - Estavam amamentando o bebê (seio ou mamadeira), 2- Serem multíparas e aceitaram participar do estudo. Como critérios de exclusão, foram utilizados: 1 - Serem portadoras de doenças infectocontagiosas ou mentais diagnosticadas.

\section{Ambiente}

O estudo foi realizado na Unidade Materno Infantil, que pertence ao Centro de Recuperação Feminino (CRF) e está localizada no município de Ananindeua. A unidade é coordenada pela Superintendência do Sistema Penitenciário do Estado do Pará (SUSIPE), inaugurada em março de 2013 é a primeira da Região Norte a acolher internas grávidas a partir do sexto mês de gravidez permanecendo na Unidade até a criança completar 12 meses.

\section{Instrumentos}

Os dados foram coletados através de um roteirodeentrevistasemiestruturadacriadopelapesquisadoracom o objetivo de levantarinformaçõesparadescreveroperfildasmãesebebês.O roteiro foi composto por 13 questões que contemplaram: dados sócio demográficos, situação jurídica, dados do bebê e registros sobre o ambiente (físico e social).
Foi utilizado também, o inventário de Conhecimento do Desenvolvimento Infantil (KIDI, KnowledgeofInfantDevelopmentInventory), instrumento elaborado por Macphee (1981). No Brasil, foi traduzido e adaptado por Ribas, Moura, Gomes e Soares (2000). O instrumento avalia a proporção de conhecimentos considerados corretos, relacionados aos períodos mais prováveis para aquisição de determinadas habilidades pela criança, como as motoras, perceptuais e cognitivas; fatores relacionados ao desenvolvimento, práticas parentais, além de cuidados adequados com a alimentação, higiene e segurança. Possui 75 questões de múltipla escolha, porém as formas de responder variam dependendo da fase do inventário. Na primeira fase o responder da mãe envolve avaliar de concordo, discordo ou não estou certa segundo a assertiva dada; na segunda fase as respostas de escolha são: concordo, mais jovem, mais velho, e não estou certo; e na terceira fase a resposta deve ser escolhida em uma das opções: a,b,c,d, e não tenho certeza. $\mathrm{O}$ instrumento se divide em quatro categorias, assim definidas por Macphee (1981): práticas parentais (14 itens), normas e marcos do desenvolvimento (32 itens), princípios (17 itens) e saúde (12 itens).

\section{Procedimento}

Foi solicitada autorização do superintendente do sistema penitenciário do Estado, para implementação de visitas sistemáticas à instituição e facilitar os primeiros contatos com as mulheres e o acesso às dependências. Ao mesmo tempo, a autorização do comitê de ética foi solicitada e foi apresentada a UMI possibilitando a coleta de dados. Antes do início da coleta, a pesquisadora passou por um período de habituação no contexto de cárcere, que objetivou conhecer a estrutura física da unidade, sua rotina de funcionamento, as mães e seus bebês, além da equipe multiprofissional da unidade.

A coleta de dados foi realizada de período de Fevereiro de 2015 a Agosto de 2016. Para a realização das entrevistas, o material utilizado (formulário do perfil das participantes, o KIDI e as folhas de respostas)forampreviamente organizados, assim como o pedido de autorização para uso de gravadordentro da instituição.

Os dados sócios demográficos referentes às mães foram organizados em um banco de dados no Software SPSS 20, nele foi realizado um cálculo para obter a porcentagem com base na frequência dos dados que possibilitou a caracterização das participantes. Os dados doInventário de Conhecimento do Desenvolvimento Infantil (KIDI) foram lançados e analisados tanto em uma 
planilha do SPSS como do programa Excel. Os registros sobre o ambiente (físico e social) foram agrupados a partir de determinadas características: estrutura do espaço e atividades de rotina.

\section{Resultados e Discussão}

Características das mães e o ambiente físico e social

As mães da amostra tinham idade acima de 25 anos, solteiras $(56,3 \%)$, multíparas, custodiadas provisórias, residindo no interior do Estado, com ensino fundamental, presas por envolvimento com o tráfico de drogas e estavam há oito meses na Unidade. Com exceção da idade e tempo passado na Unidade, verifica-se semelhança com os perfis de outras mães em situação privativa de liberdade em várias regiões do Brasil (Braga \&Angotti, 2015;Simas,Ventura \&Larouzé,2015; Lima, Pereira Neto, Amarante, Dias \& Ferreira Filha ,2013).

As variáveis de idade, multiparidadee tempo passado na Unidade, indicam mulheres em fase reprodutiva, com outros filhos extramuros e permanência com seus bebês durante o período de amamentação. Em consonância com a constituição Federal Brasileira e com o Estatuto da Criança e do Adolescente é dever do Estado assegurara à mulher presa as condições para que possa permanecer com seus filhos durante o período de amamentação, assegurando espaços adequados para essa prática.

A Unidade Materno Infantil foi adaptada para receber as mães e seus bebês. A estrutura física é composta por um pátio de entrada com uma sala adjacente, três quartos amplos, três banheiros e um lavabo, uma enfermaria, uma sala de administração, cozinha e nos fundos da residência o refeitório. Os quartos são amplos, possuem leitos acompanhados de um berço menor, são equipados com televisão, aparelho de DVD, centrais de ar-condicionado, armários e estantes fixadas nas paredes, geralmente preenchidas com brinquedos os quais ficam disponíveis para uso. Os banheiros possuem pia, boxe, chuveiro, privada e banheira. A enfermaria é equipada com maca, instrumentos médicos, uma central de ar-condicionado e um banheiro, onde são realizados atendimentos multiprofissionais buscando a melhoria da saúde das mães e de seus bebês, através de orientações, avaliações e acompanhamentos, entrega de vitaminas e/ ou medicamentos, fraldas e outros materiais de higiene.

A área da cozinha é exclusiva das custodiadas e destinada para o preparo dos alimentos dos bebês, visto que as refeições para as mães são trazidas por um serviço terceirizado e entregues em horários certos todos os dias. O refeitório é o local onde as mães se reúnem para as refeições do dia e também para receberem visitas. Atualmente, o espaço está equipado com uma brinquedoteca móvel que disponibiliza brinquedos, materiais e livros. Esta objetiva estimular de forma lúdica, o vínculo entre a mãe e o bebê, e a participação ativa da mãe no desenvolvimento do seu filho. No jardim as mães saem para tomar sol em horários certos do dia, assim como realizam tarefas domésticas para a manutenção da unidade.

Os contatos com os familiares são efetivados pelo recebimento de ligações telefônicas, uma vez por semana, com mediação da assistente social, e visitas quinzenais (sextas feiras para as crianças e sábado para adultos). Pode-se perceber uma divergência entre os dados informados sobre o receber visitas e as observações do ambiente social. Foi constatado que as mães e seus bebês passavam longos períodos sem o contato físico com seus familiares e/ou conhecidos. Apesar dos dias de visitação existirem, sua efetivação era difícil, na maioria das vezes devido à distância de moradia dos seus familiares em relação a UMI e dificuldades financeiras para transporte e manutenção na cidade. Assim, os bebês estão crescendo afastados do convívio de demais familiares, tendo a mães e demais crianças e adultos na Unidade como parceiros.

A interação íntima com a mãe em detrimento de outros familiares, torna-se um complicador quando chegar a hora de iniciar o processo de separação. Nas diretrizes para a convivência mãe filho/a no sistema prisional (Brasil, 2016) esta enfatizado, que a saída da criança dever ser preparada e implementada mediante medidas específicas, desenvolvidas pelas equipes interdisciplinares do estabelecimento prisional em articulação com o Centro de referência de Assistência Social que promoverá o acompanhamento social e familiar posterior.Como na Unidade as visitas são raras, o desligamento ocorre de forma abrupta, realidade que pode ser contornada com medidas que facilitem a manutenção dos vínculos familiares.

O espaço proporciona um leito para cada interna e um armário para guarda de pertences, contudo, a privacidade é baixa e as interações constantes. Foi possível identificar situações de conflitos (por barulho no espaço, cobrança de tarefas não realizadas, desaparecimento de alimentos, desobediência asrotinascasa, querelas pessoais etc.). Masexistiramtambém, situações de cooperação entre as mães (carregar o bebê de outra e amamentação cruzada, banha e vestir o bebê de outra, preparar a decoração para os aniversários), de consolo para com a outra,de trocas de experiências acerca da maternidade e manifestação de emoção (choros e risos) quando da saída da díade por 
alvará. Esse cenário indicaque a maternidade vivida no cárcere se diferencia da maternidade extramuros.

\section{Conhecimento das mães sobre desenvolvimento e práticas de cuidado}

O KIDI foi aplicado com dois propósitos, aferir o conhecimento e discutir as práticas. No geral as mães custodiadas acertaram $62 \%$ das questões que compõem as quatro categorias doinstrumento. Considerando as características de perfil dessas mães, em especial a multiparidade e baixa escolaridade, os dados divergem da literatura que indica maior nível de escolaridade associado a mais conhecimentos sobre o desenvolvimento infantil.

Apesar do número de acertos global, a análise por categoria indica os melhores resultados em assertivas relacionadas a categoria Saúde e Segurança $(71,87 \%)$ e princípios do desenvolvimento $(64,34 \%)$. O trabalho desenvolvido pela equipe de saúde e a multiparidadepodem estar ligadas a esse desempenho. Como a maioria das mães possuem de dois a três filhos, logo deve-se considerar as experiências vivenciadas e passadas com estes, assim como o apoio e orientações recebidas de outros familiares, o que nos remete aos ensinamentos passados de geração em geração através de crenças e valores, reafirmando a influência inerente da psicologia dos cuidadores, como colocado por Harkness e Super (1986).

A categoria Princípios de desenvolvimento versa sobre aquisição progressiva de competências e a descrição de habilidades gerais da criança. O fato de serem multíparas podem ser usados como argumento para os acertos, provavelmente devido a experiência adquiridas durante o processo de desenvolvimento de outros filhos. Além disso, deve-se ressaltar que na UMI as mães entram grávidas e acompanham de forma direta o processo de desenvolvimento dos bebês das outras mães até que tenham os seus. De certa forma acrescenta no conhecimento sobre o desenvolvimento infantil que possuem. As práticas de cuidado também eram compartilhadas entre as mães, devido a rotina da unidade a maioria dos cuidados com os bebês ocorria em conjunto, como o horário de serem alimentados (exceto os bebês que só mamavam), de tomarem banho, tomar sol, dormirem e acordarem.

A categoria normas e marcos do desenvolvimento que descreve o conhecimento das mães sobre períodos mais prováveis para a aquisição de habilidades motoras, perceptuais e cognitivas da criança teve menos acertos. Uma possível explicação seja devido à ausência de divulgação desse tipo de informação para as mães, tendo em vista que questões relacionadas aos períodos de aquisição de habilidades geralmente são difundidas em meios acadêmicos, logo ressalta-se a escolaridade das mães que em sua maioria tem o ensino fundamental o que dificulta o acesso a essas informações.

Entre as questões com maior percentual de erro destaca-se a que versa sobre os cuidados em relação a saúde do bebê quando este apresenta diarreia. Nesse caso, deve-se considerar o tempo, o local e a população que o instrumento pretendia atender, pois provavelmente o alto índice de erro se deu devido as realidades rurais e econômicas diferentes da população a qual o instrumento se destina, ressaltando que a mãe tem como cidades de origem interiores do estado do Pará, em que geralmente o refrigerante não é usado dentro das práticas parentais voltadas para a saúde do bebê. Estudos como de Super (1976) afirmam a influência do ambiente físico nas práticas de cuidado, em seu estudo foi possível mostrar como os aspectos do ambiente físico e social estariam relacionados a determinadas questões do desenvolvimento, assim como a relevância das práticas adotadas pelos cuidadores. Além disso, questões relacionadas ao tempo que um recém-nascido dorme e chora por dia também foram significativas, trazendo a reflexão acerca da noção de tempo das mães quando estas estão longos períodos custodiadas e sem acesso a relógios, e consequentemente as horas.

Neste sentido, foi identificado que o ambiente físico e social da Unidade apresentam elementos que podem influenciar no desenvolvimento dos bebês, tais como: a baixa frequência de visitas dos familiares (fragilização dos vínculos); a Inexistência de privacidade (potencialização de comportamentos agressivos e/ou depressão); rigidez na rotina (compromete a motivação para o engajamento em outras atividades); elementos estes que podem dificultar a vinculação mãe e bebê. Por outro lado, encontramos elementospositivos, tais como: o acompanhamento constante da saúde das mães e seus bebês pelos profissionais da unidade; a aproximação e apoio da equipe técnica; o ambiente físico ser característico de uma residência e ser equipado com o mínimo necessário para os cuidados das mães e os bebês.

\section{Considerações Finais}

O presente estudo se propôs a analisar o contexto da Unidade Materno Infantil à luz da teoria do Nicho de desenvolvimento (Harkness e Super, 1986), buscando a compreensão dos elementos que constituem o ambiente físico e social, as práticas de cuidado e o conhecimento das mães acerca do desenvolvimento infantil.Os dados 
permitiram uma descrição do ambiente físico e social e realçaram um ambiente propício para a estimulação do desenvolvimento infantil, quanto ao aspecto social, pode-se sugerir um maior engajamento da unidade na prestação de visitas e mediação telefônica com os familiares e conhecidos.

Ainda são necessárias pesquisas no contexto de cárcere que possam acompanhar as mudanças regionais e nacionais, em um movimento contrário ao de exclusão e negação da realidade dessas mães e seus bebês. Vale ressaltar o caráter exploratório do estudo e as limitações existentes, sendo difícil a generalização dos resultados pois o mesmo investigou uma amostra relativamente pequena proveniente apenas de um contexto. Neste ponto evidencia-se a necessidade da continuação da realização de estudos descritivos nesse contexto, que utilizem sessões observacionais para que possam contemplar de forma mais sistemática o aspecto das práticas parentais exercidas e estudos comparativos que possam abarcar mães em liberdade para uma melhor compreensão da influência do contexto do cárcere.

Os resultados do presente estudo se somam aos dados da literatura nacional acerca das mães em situação de privação de liberdade, como uma contribuição para a caracterização sócio demográfica das mães paraenses e para a compreensão de seus conhecimentos acerca do desenvolvimento infantil em determinado contexto. Somam-se também aos dados da literatura que apontam a relevância do contexto e das crenças como influenciadores das práticas parentais.

\section{Referências}

Armelin, B. D. F, Mello, D. C., \&Gauer, G. J. C. (2010). Filhos do cárcere: estudo sobre as mães que vivem com seus filhos em regime fechado. Programa de pós-graduação em ciências criminais-PUCRS: RS.

Braga, A. G. M., \&Angotti, B. (2015). Dar à luz na sombra: condições atuais e possibilidades futuras para o exercício da maternidade por mulheres em situação de prisão. Série Pensando o Direito, 51.

Brasil. Ministério da justiça (2012).Relatório final do I workshop - atenção aos filhos de mulheres em situação de privação de liberdade. Departamento Penitenciário Nacional;Diretoria de políticas penitenciárias; comissão especial - projeto Mulheres.

Brasil. Ministério da justiça (2016). Diretrizes para a convivência mãe filho/a no sistema prisional. Departamento Penitenciário Nacional;Diretoria de políticas penitenciárias; Coordenação de políticas para as mulheres e promoção das diversidades.

Centro pela Justiça e pelo Direito Internacional - CEJIL. (2007). Relatório sobre mulheres custodiadas no Brasil.

Dalmácio, L. M., Cruz, E. J. S., \& Cavalcante, L. I. C. (2014). Percepções de mães custodiadas sobre o direito á amamentação no sistema prisional. Revista Brasileira de História \& Ciências Sociais, 6(11), 54-72.

Harkness, S., \&Super, C. M. (1986). The developmental niche: a conceptualization at the interface of child and culture. InternationalJournalofBehavioralDevelopment, 9, 545-569.
Harkness, S. \&Super, C. M. (1992). Parental ethnotheories in action. In I. E. Siegel, A.V. McGillicuddy-DeLisi\& J. J. Goodnow (Eds.). Parental belief systems: The psychological

consequences for children, 373-391.

Lima, G. M. B., Pereira Neto, A. F., Amarante, P. D. C., Dias, M. D., \& Ferreira Filha, M. O. (2013). Mulheres no cárcere: significados e práticas cotidianas de enfrentamento com ênfase na resiliência. Saúdeem Debate, 37(98), 446-456.

Macphee, D. (1981). Manual for the Knowledge of Infant Development Inventory.Manuscritonãopublicado, Universityof North Carolina.

Ribas Jr., R. C., Moura, M. L. S., Gomes, A. A. N., \& Soares, I. D. (2000). Adaptação brasileira do Inventário de Conhecimento sobre o Desenvolvimento Infantil de David Macphee [Resumo]. In Sociedade Brasileira de Psicologia do Desenvolvimento (Org.), Anais - III Congresso Brasileiro de Psicologia do Desenvolvimento (pp. 183). Niterói, RJ: Autor.

Rita, R. P. S. (2006). Mães e crianças atrás das grades: em questão oprincípio da dignidade da pessoa humana. (Dissertação de Mestrado em Política Social). Universidade de Brasília, Brasília.

Santos, R. C. S. (2011). Maternidade no cárcere: reflexões sobre o sistema penitenciário feminino. (Dissertação de Mestrado em Política Social). Universidade Federal Fluminense, Niterói, Rio de Janeiro.

Simas, L., Ventura, M., Baptista, M. R., \&Larouzé, B. (2015). A jurisprudência brasileira acerca da maternidade na prisão. Revista Direito GV, 11(2), 547-572.

Souza, R. G. C., Ferreira, A. M. M. (2012). O amor atrás das grades:um estudo sócio- jurídico sobre a maternidade nas prisões. Revista da FARN, 11(1/2): 133-163.

Super, C. M. (1976). Environmental effectson motor development: The case of "Africaninfantprecocity". Develop. Med. ChildNeurol. 18, 561 -567.

Viafore, D. (2005). A gravidez no cárcere brasileiro: uma análise da penitenciária feminina Madre Pelletier. Revista Direito \& Justiça, 31 (2), 91-108.

Submetido em: 29-5-2017

Aceito em: 11-12-2017 